OPEN ACCESS

Edited by: Carlos Rosales,

National Autonomous University of Mexico, Mexico

Reviewed by:

Xiang-Yang Wang,

Virginia Commonwealth University, United States

Chunqing Guo,

Virginia Commonwealth University,

United States

${ }^{*}$ Correspondence:

Stuart K. Calderwood

scalderw@bidmc.harvard.edu

Specialty section This article was submitted to

Molecular Innate Immunity, a section of the journal

Frontiers in Immunology

Received: 07 November 2019 Accepted: 11 December 2019

Published: 10 January 2020

Citation:

Murshid A, Borges TJ, Bonorino C, Lang BJ and Calderwood SK (2020) Immunological Outcomes Mediated Upon Binding of Heat Shock Proteins to Scavenger Receptors SCARF1 and

LOX-1, and Endocytosis by Mononuclear Phagocytes.

Front. Immunol. 10:3035

doi: 10.3389/fimmu.2019.03035

\section{Immunological Outcomes Mediated Upon Binding of Heat Shock Proteins to Scavenger Receptors SCARF1 and LOX-1, and Endocytosis by Mononuclear Phagocytes}

\author{
Ayesha Murshid ${ }^{1}$, Thiago J. Borges ${ }^{1,2}$, Cristina Bonorino ${ }^{3,4}$, Benjamin J. Lang ${ }^{1}$ and \\ Stuart K. Calderwood ${ }^{1 *}$ \\ ${ }^{1}$ Department of Radiation Oncology, Beth Israel Deaconess Medical Center and Harvard Medical School, Boston, MA, \\ United States, ${ }^{2}$ Renal Division, Schuster Family Transplantation Research Center, Harvard Medical School and Brigham and \\ Women's Hospital, Boston, MA, United States, ${ }^{3}$ Laboratório de Immunoterapia, Departmento de Ciências Básicas da \\ Saúde, Universidade Federal de Ciências da Saúde de Porto Alegre, Porto Alegre, Brazil, ${ }^{4}$ Department of Surgery, School of \\ Medicine, University of California, San Diego, San Diego, CA, United States
}

Heat shock proteins (HSP) are a highly abundant class of molecular chaperones that can be released into the extracellular milieu and influence the immune response. HSP release can occur when cells undergo necrosis and exude their contents. However, HSPs are also secreted from intact cells, either in free form or in lipid vesicles including exosomes to react with receptors on adjacent cells. Target cells are able recognize extracellular HSPs through cell surface receptors. These include scavenger receptors (SR) such as class E member oxidized low-density lipoprotein receptor-1 (LOX-1, aka OLR1, Clec8A, and SR-E1) and scavenger receptor class F member 1 (SCARF1, aka SREC1). Both receptors are expressed by dendritic cells (DC) and macrophages. These receptors can bind HSPs coupled to client binding proteins and deliver the chaperone substrate to the pathways of antigen processing in cells. SR are able to facilitate the delivery of client proteins to the proteasome, leading to antigen processing and presentation, and stimulation of adaptive immunity. HSPs may also may be involved in innate immunity through activation of inflammatory signaling pathways in a mechanism dependent on SR and toll-like receptor 4 (TLR4) on DC and macrophages. We will discuss the pathways by which HSPs can facilitate uptake of protein antigens and the receptors that regulate the ensuing immune response.

Keywords: heat shock proteins, scavenger receptor, immunity, macrophage, dendritic

\section{INTRODUCTION}

Heat shock proteins (HSPs) are the major components of a primordial cellular responses to proteotoxic stress, and the resultant production of many HSP species is collectively described as the heat shock response (HSR) (1) (Table 1). Classic activators of the HSR such as heat shock, lead to rapid denaturation of intracellular proteins resulting in dysfunctional intermediate 
TABLE 1 | Mammalian heat shock proteins.

\begin{tabular}{lllll}
\hline $\begin{array}{l}\text { HSP } \\
\text { type }\end{array}$ & Intracellular role & Extracellular role & Receptor & References \\
\hline Hsp27 & Prevents protein & Inflammatory & TLRs & (2) \\
& Aggregation & & & \\
Hsp60 & Chaperonin & inflammatory? & TLR4? & $(3)$ \\
Hsp70 & Initial stages of & Inflammatory? & SR, CD91 & $(4-7)$ \\
& Protein folding & immune & TLR4? & $(8-10)$ \\
Hsp90 & Folding to the & Antigen chaperone & SR, CD91 & $(11-13)$ \\
& Functional state & Cell motility & & $(14,15)$ \\
Hsp110 & Chaperone & Antigen chaperone & SR & $(16,17)$ \\
\hline
\end{tabular}

conformational states that are prone to aggregation. Cell survival necessitates an almost immediate and abundant induction of the HSPs that halt the aggregation cascade and permit refolding of cellular proteins and restoration of normal protein function (18). Beyond protein refolding, HSPs also function to facilitate trafficking of their client substrates between subcellular compartments and mediate protein-protein interactions. They are hence referred to as molecular chaperones $(18,19)$. The HSP family contains a number of members that belong to different protein families, but each has in common a role in stepwise protein folding (Table 1) $(2,4,5)$. However, in addition to their various intracellular functions, HSPs have also been detected in the extracellular spaces and circulation. This phenomenon may be the result of the death of stressed cells and release of the highly amplified HSP cohort (6). Although HSPs lack the leader sequences required for the classical secretion pathways (20) they may be released from viable cells by non-canonical secretion pathways (21). Alternative mechanisms of HSP secretion have been described. These pathways include the secretion of free Hsp70 by a pathway similar to that utilized for non-canonical secretion of interleukin-1 beta, involving secretory lysosomes, or alternatively HSPs may be packaged in lipid vesicles known as exosomes and released to the extracellular milieu of tumors and normal tissues $(7,21-23)$. The extracellular HSPs may exert a number of effects on adjacent cells after their secretion, such as activation of antigen-presenting cells (APCs), including monocytes, dendritic cells (DC) and macrophages, as well as causing increased mobility and metastasis in target cells as has been observed in wound healing and cancer scenarios (3, 24-26). Hsp70 and Hsp110 have been utilized effectively in anticancer vaccines, in which they function as carriers of antigenic peptides that can be efficiently taken up and processed by APCs and presented to T lymphocytes $(8,9,16,17,27-$ 29). Understanding how HSPs are bound by acceptor cells and taken up is therefore important in determining the properties and function of extracellular HSPs.

\section{AN OVERVIEW OF HSP RECEPTORS}

Most of the biological effects of extracellular HSPs identified to date have involved their binding to surface receptors on target cells prior to their internalization $(10,30)$. However, the entire spectrum of dedicated high affinity receptors for the HSPs have not been identified in studies carried out so far. The first protein to be identified as an HSP receptor was CD91/alpha2 macroglobulin receptor, which is a low density lipoprotein (LDL) binding protein currently known to be a highly versatile receptor for over 30 other ligands (31). This multi-subunit protein appears to be a common receptor for most of the HSPs involved in immune responses. There was some controversy originally regarding the significance of this finding, as CD91 was suggested to be the receptor involved in antigen cross-presentation by DC in response to HSP vaccines, although most types of DC do not appear to express endogenous CD91 (11, 30). However, CD91 has since been shown to be a receptor for Hsp90 $\alpha$ in wound healing and cancer metastasis scenarios and signaling pathways downstream from the receptor appear to mediate effects of the chaperone on cell motility, a key property in wound healing and metastasis (32). The class E and F scavenger receptors LOX-1 and SCARF1 are the major receptors for HSP-peptide complexes, mediating antigen uptake and processing $(10-12,33)$ (Figure 1). The scavenger receptors, although not structurally related, share common functions including the binding, endocytosis and thus detoxification of oxidized LDL by vascular endothelial cells (33, 34). They are key players in the removal of oxidized LDL from the circulation and protection from the morbidity associated with atherosclerosis (35). Both LOX-1 and SREC1 are also expressed on DC and macrophages and play key roles in antigen crosspresentation mediated by HSP- peptide complexes (HSP-PC) $(11,36)$. In this review, we will describe the roles of these SR members in mediating extracellular HSPs-triggered responses, focusing mainly in their interaction with the Hsp90 $\alpha$. A really puzzling feature of this system is that most SR members are not structurally related but bind to a common ligand, while HSPs of different chaperone families often bind to the same scavenger receptor species, although also lacking structural relationship $(12,33)$ (Figure 1, Table 1).

It is not clear which property of HSPs prompts their binding to scavenger receptors. However, in addition to binding to oxidized LDL, members of the scavenger receptor family can bind to proteins with other modifications (acetylated LDL) as well as to polyanionic ligands such as poly-IC, findings which may cast some light on interactions with HSPs $(11,33)$. HSPs have been shown to be phosphorylated and acetylated, modifications that would increase their net negative charge $(37,38)$. Future studies would be required to clarify this issue. When LDL particles are oxidized, they assume a net negative charge and additionally phospholipid moieties are added to the LDL particle protein apolipoprotein B100 (39-41). These phospholipid residues fit into a hydrophobic tunnel formed by surface LOX-1 dimers (42). HSP binding to scavenger receptors may therefore involve the ability of the chaperones to recognize hydrophobic patches on client proteins as well as the charge interactions mentioned above (5).

\section{HSP RECEPTORS AND DETOXIFICATION OF HSP-PEPTIDE COMPLEXES AND DEAD CELLS}

The primary role of the scavenger receptor family seems to be removal of oxidized LDL from the circulation (35). It is 


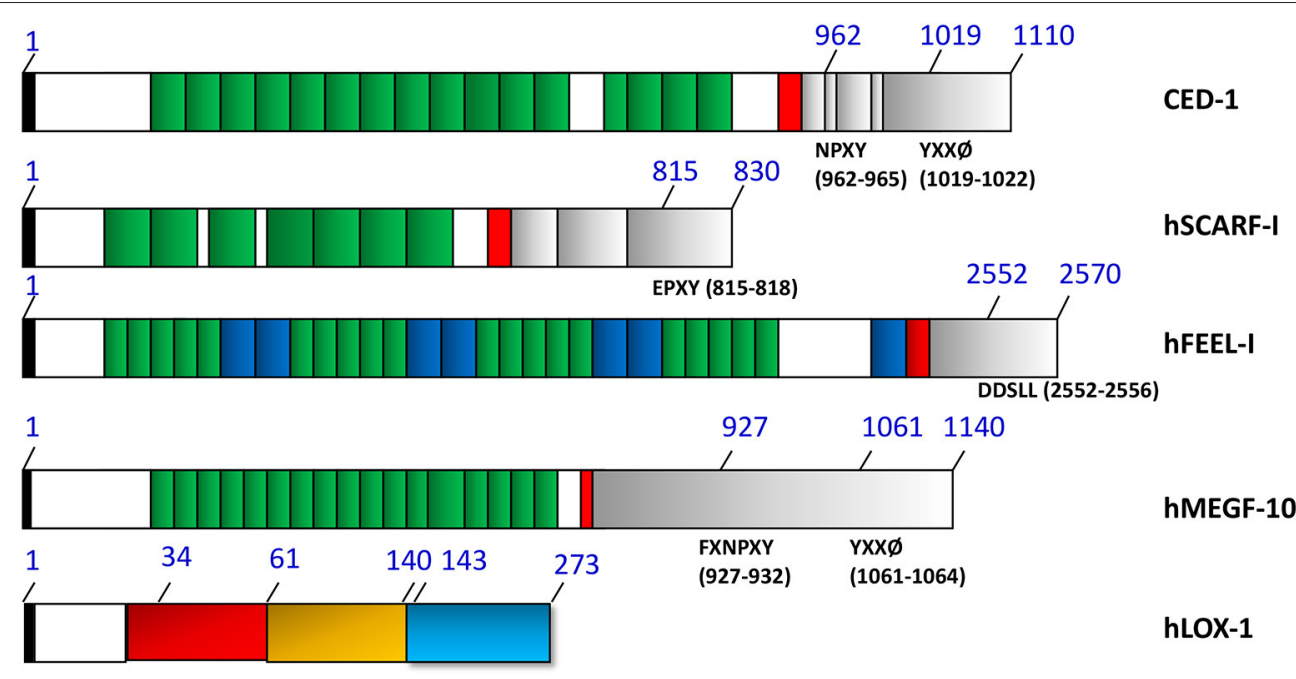

Signal Peptide

Atypical EGF-like domain

Neck/Stalk domain

Transmembrane domain

C-type lectin-like (CTLD) recognition domain

Fasciclin domain

Cytosolic domain

FIGURE 1 | The domain structures of HSP binding and related cell surface receptors.

also possible that this role may be recapitulated in interactions with HSP-PC, a complex which may flood the local circulation after tissue trauma, a result of the large scale cell death by necrosis that may ensue. Such complexes may be able to prime immune and inflammatory responses in damaged tissues and it may be incumbent on mononuclear phagocytes to rapidly bind and endocytose such structures using the scavenger receptors $(43,44)$. It is known that LOX-1 and SCARF1 can also bind cell corpses and remove them from the extracellular spaces $(45,46)$. Uptake of HSP-PC may thus be part of a general detoxification process exerted by scavenger receptors, operating in damaged tissues. The scavenger receptors could also be involved in uptake and removal of HSP-containing exosomes given their abilities to bind lipid structures such as oxidized LDL and cell corpses (46). SCARF1 is a paralog of the cell corpse receptor CED1 expressed in C. elegans $(35,47)$. In addition, more closely related paralogs of CED-1 have been unearthed and could be putative HSP receptors. These include Drosophila gene draper and the mammalian MEGF10, MEGF11, and MEGF12 (4851). Each of these proteins contains multiple EGF-like motifs in the extracellular domain that may be recognition sequences for apoptotic bodies and play roles in dead cell clearance (Figure 1). Another protein with multiple EGF-like motifs in its extracellular domain that can bind to HSPs and apoptotic cell corpses is the Class $\mathrm{H}$ scavenger receptor FEEL-1/stabilin-1 $(30,33,52)$ (Figure 1). Its role in responses to extracellular HSPs is currently unclear.

\section{PATHWAYS OF SCAVENGER RECEPTOR-MEDIATED ENDOCYTOSIS}

The properties of the SR as endocytic receptors with a wide range of selectivity makes them effective intermediaries in sampling the local extracellular milieu of APC for potentially antigenic molecules. Thus, both LOX-1 and SCARF1 are expressed in DC and other mononuclear phagocytes $(11,36)$. There are a number of pathways by which extracellular molecules can enter cells. These include endocytosis, a process which involves the association of molecules with cell surface invaginations, uptake in an actin-dependent manner, and then fusion of the engulfed vesicles with intracellular endosomes. The major canonical pathway is clathrin-mediated endocytosis, a process that involves pit-like structures inserted into the plasma membrane which are lined with clathrin, a trimeric protein that stabilizes the pits (53). Molecules, sometimes associated with receptors, are then engulfed in clathrin coated vesicles that are found in the majority of cells. There is a second, less prevalent pathway, involving the protein caveolin found in structures known as caveolae, $50 \mathrm{~nm}$ invaginations that can also mediate endocytosis of extracellular molecules (54). However, both LOX-1 and SCARF1 have been shown to take up their ligands in a clathrin and dynaminindependent manner, utilizing a more unconventional endocytic pathway $(36,55)$. The mechanisms involved in endocytosis mediated through LOX-1 seem to be currently unclear although more information has accumulated regarding SCARF1. Upon 
ligand binding SCARF1 is internalized by DC via the GPI-AP (glycophosphatidylinositol-anchored proteins) enriched early endosome (GEEC) pathway (Figure 2) $(56,57)$. This pathway is mediated by uncoated tubular vesicular structures called clathrin independent carriers (CLICs) that mature into the early endocytic compartment (GEECs) $(58,59)$. The pathway is specialized for uptake of GPI-AP such as the folate receptor. Thus, uptake of Hsp90 $\alpha$ - peptide complexes was not inhibited by antagonists of clathrin- and caveolin-dependent endocytosis, characteristic of the GEEC pathway (36). Endocytosis of Hsp90 $\alpha$ peptide complexes was however inhibited by blocking the activity of Rho GTPase CDC42, a protein shown to be involved in actin polymerization and uptake of GPI-AP through the GEEC pathway. SCARF1 became co-localized, after binding to Hsp $90 \alpha-$ peptide complexes, with CD59, a marker GPI-AP protein that utilizes the GEEC pathway $(36,60)$. Proteins internalized through the GEEC pathway, such as GPI-AP are frequently associated within plasma membrane microdomains such as lipid rafts (61). These are regions of the membrane enriched in cholesterol and glycosphingolipids that are immiscible with the bulk membrane and appear to diffuse freely through this membrane $(62,63)$. SCARF1 is not a GPI-AP protein even though it has been shown to enter the GEEC pathway. However, another protein modification that may target transmembrane proteins such as SCARF1 to lipid rafts is S-acylation of cysteine residues close to the transmembrane domain with saturated palmitate residues capable of dissolving in the cholesterol and glycosphingolipid milieu that comprises the partitioned microdomains. SCARF1 contains five cysteine residues (Cys - 440, 441, 443, 444, 445) adjacent to the transmembrane domain (amino acids 422442) $(35,62,63)$. Thus, cysteine palmitoylation, and perhaps interaction with other proteins in the lipid rafts, may potentially recruit SCARF1 to this region. The nature and extent of partner proteins associated with SCARF1 in the rafts is not clear, although the receptor was shown to interact with the non-receptor tyrosine kinase c-Src (36). Although c-Src is likewise not a member of the GPI-AP family, it also associates with the rafts after S-acylation (63). Inhibition of c-Src activity prevented the cross-presentation of antigens associated with Hsp90 $\alpha$ suggesting a key role for signaling through this tyrosine kinase in the antigen presentation pathways (36). Phosphorylation of key tyrosine residues within internalization motifs in the intracellular domain regulates the endocytosis of many receptors, although consensus sequences for internalization such as the NPXY motif found in CED-1 are not observed in the SCARF1 sequence (Figure 1) (35). The mechanism of regulation of SCARF1 endocytosis by c-Src thus remains to be defined. LOX-1 function has also been linked to its entry into lipid rafts and cholesterol lowering drugs inhibit its function (64).

\section{SCAVENGER RECEPTOR-MEDIATED ACCESS TO ANTIGEN PROCESSING PATHWAYS}

Binding of antigenic polypeptides to HSPs in DC allows them to enter the pathway of antigen cross presentation and be processed

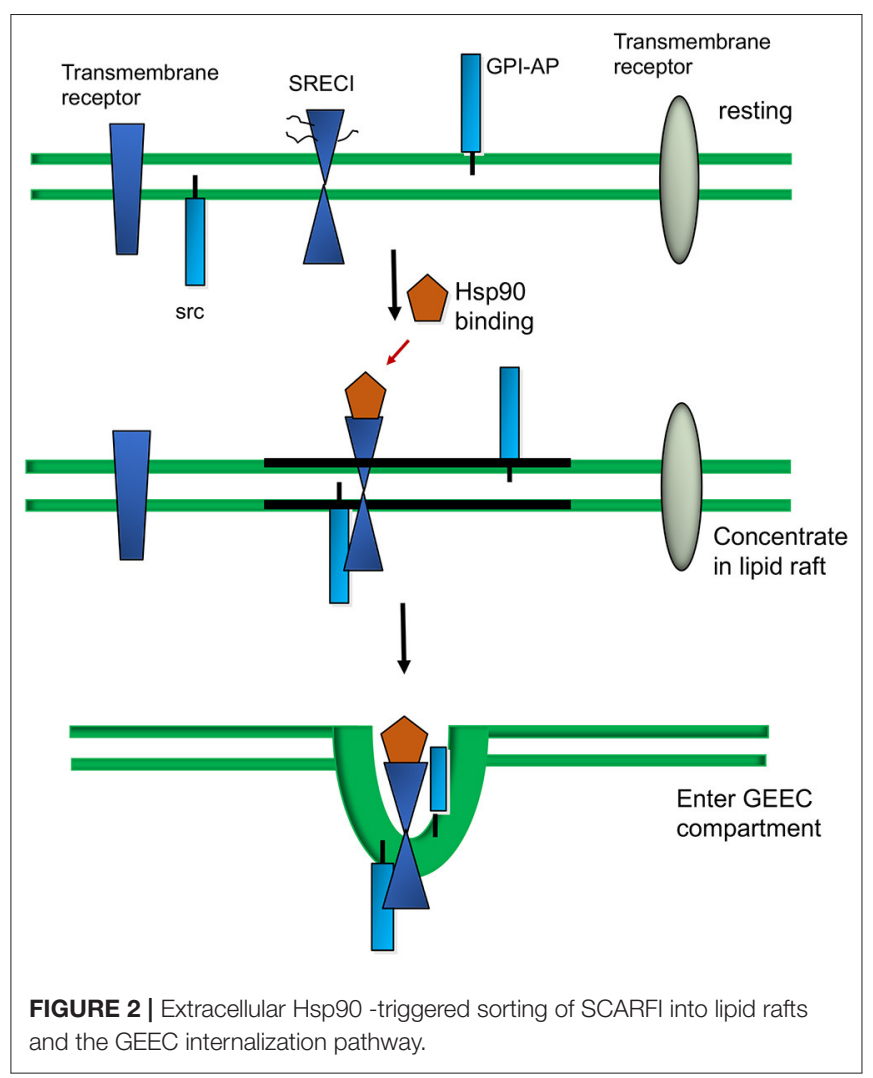

in the cytoplasm and presented on major histocompatibility Class I (MHC I) proteins (13). Most of the antigens presented on MHC Class I proteins are derived from proteolytic processing of intracellular proteins via the classical Class I pathway (65). However, DC are specialized to take up extracellular antigens using receptors such as Fc, CLEC9A, DC-SIGN, DEC205 and mannose receptor, and thus funnel them into the Class I pathway, permitting surveillance of the extracellular spaces (66-70). HSPs can also bind external antigens and funnel them into the Class I pathway through LOX-1 and SCARF1 (36). For instance, following transit through the GEEC compartment, Hsp $90 \alpha-$ peptide-SCARF1 complexes are translocated to early endosomes (36). In the case of full-length chaperoned proteins such as intact ovalbumin, antigen processing is carried out after its digestion in the proteasome in the cytoplasm and then antigenic peptides are taken up into MHC class I molecules by TAP (transporter associated with antigen processing) in the ER (36). This latter process clearly requires the chaperoned protein to escape the confines of the early endosome and enter the cytoplasm in order to be taken up by the proteasome. Hsp90 $\alpha$ is known to facilitate this step as well as to maintain the client protein intact until it reaches the proteasome (71). Hsp90 $\alpha$-peptide complexes internalized in association with SCARF1 can also be processed within the endosome and antigens loaded onto MHC class II molecules prior to recycling to the plasma membrane (14). This is an essential step in efficient activation of T cell immunity and the activation of CD4+ T helper cells. Normally uptake of soluble antigens into the Class I and Class II pathways involves separate 


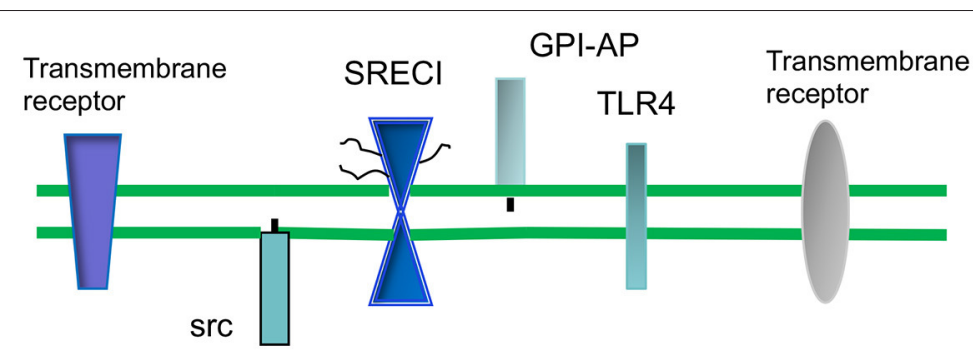

HSP

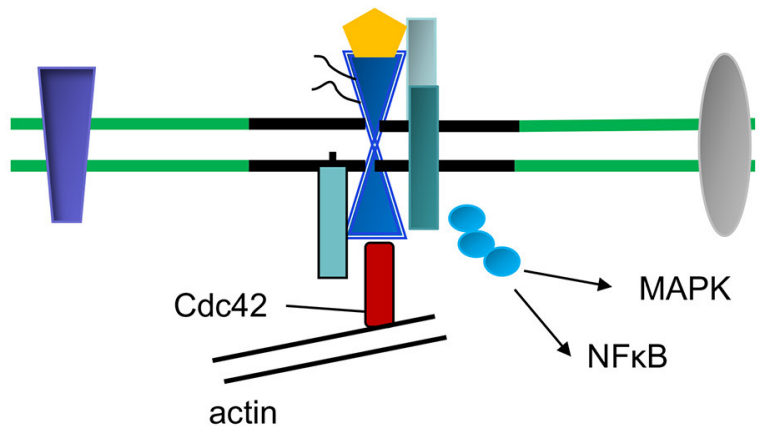

resting

HSP binding

\section{Concentrate}

in lipid raft

FIGURE 3 | HSP-induced cell signaling and inflammation.

receptors (13). This scavenger receptor can therefore facilitate antigen processing by APC through the two major antigen presentation pathways and appears to play an integral role in the functioning of HSP based immunity (13). LOX-1 also participates in processing of HSP bound tumor antigens and approximately $50 \%$ of ovalbumin (sample antigen) cross-presentation appeared to be mediated through this receptor (36). Although HSP-PC binding to SCARF1 can facilitate antigen presentation through the MHC class I and class I pathways it is not clear whether this interaction can induce co-receptor induction in APC- a crucial step in adaptive immunity. For instance, creation of efficient anticancer vaccines employing large HSP family members has employed fusion of the HSPs to prokaryotic danger signals to boost inflammatory signaling and co-receptor induction (9). Interestingly, SCARF1 expression and Hsp70 vaccine anti-tumor activity is dependent on TLR2 and TLR4 function suggesting upregulation in inflammatory conditions (28).

\section{LIPID RAFTS AND CELL SIGNALING AFTER HSP BINDING TO CELL SURFACE RECEPTORS}

In addition to the import of tumor antigens by DC, HSPs may carry out key cell signaling roles within the lipid rafts of mononuclear phagocytes. The association of proteins with lipid rafts may permit them to concentrate at foci within the plasma membrane. This property depends on the ability of the rafts to diffuse within the bulk membrane and thus potentially bring together cooperating signaling molecules $(62,63,72)$. As mentioned above, an example of this process is the association of SCARF1 with c-Src after Hsp90 $\alpha$ binding, an interaction that may promote endocytosis and phagocytosis through activation of the kinase, recruitment of Cdc42 and association with the actin cytoskeleton (36) (Figure 3). SCARF1 entry into c-Src containing lipid rafts was also required for inflammatory cytokine release in mouse macrophages (73). This process involved association of SCARF1 with the pro-inflammatory Toll Like Receptor 4 (TLR4) after exposure to bacterial lipopolysaccharides (15). The association with SCARF1 in lipid rafts led to downstream signaling through TLR4, activation of the c-jun kinase, p38 MAP kinase and NF-kB signaling pathways and upregulation of interleukin 6 synthesis (73) (Figure 3). These inflammatory signaling processes required cholesterol, actin polymerization and CDC42 activity. SCARF1 and LOX-1 may also be able to recruit other signaling molecules and exposure to outer membrane protein A (OmpA) from Klebsiella pneumoniae led to recruitment of TLR2 and cytokine synthesis by the scavenger receptors (74). SCARF1 also cooperates with TLR2 in recognition of hepatitis virus non-structural protein by DC (75). In a similar vein, SCARF1 was shown to associate with TLR3 after exposure of macrophages to double stranded RNA and stimulate signaling 
through the NF-kB, MAP kinase and the IRF3 pathways (76). SCARF1 and LOX-1 may therefore play key roles in associating with cell signaling molecules and creating activating foci through the concentration of lipid rafts after binding eukaryotic or prokaryotic ligands $(73,76-78)$.

\section{SCARF1, LOX-1, AND INFLAMMATION}

While it is clear that SCARF1 and LOX-1 can mediate immunity by binding HSP-associated antigens and promoting antigen cross-presentation, the effects of HSPs on inflammation are less clear (79). Discrepancies in the field were originally ascribed to the use by some investigators of purified HSPs associated with bacterial PAMPs: indeed, HSP and endotoxins undergo complex interactions that mediate inflammatory responses (80). However, Hsp70-TLR4 association and subsequent inflammatory signaling is regularly observed in vivo and under conditions in which endotoxin contamination of the chaperones seems unlikely [reviewed in (81)]. Nonetheless, in the case of purified $\mathrm{Hsp} 90 \alpha$, it was shown that while both this chaperone and LPS could bind to SCARF1 and lead the receptor to enter a lipid raft compartment, only exposure to LPS led to significant levels of pro-inflammatory signaling through this mechanism; Hsp90 $\alpha$ alone, although entering the lipid raft compartment did not trigger inflammatory signaling (73). In addition, it has been shown that some prokaryotic HSP paralogs tend to be antiinflammatory in contrast to the mammalian isoforms (82). The answer to this conundrum appears to be at least partially that another key class of HSP receptors is expressed on mononuclear phagocytes-the sialic acid-binding immunoglobulin-type lectins (Siglecs) $(83,84)$. The Siglec family of receptors bind to selfsialic acid residues either in cis or in trans and this interaction leads to suppression of inflammatory responses in mononuclear phagocytes (83). Upon binding to the antigen, the intracellular regions of the Siglecs become activated by phosphorylation of immunosuppressive ITIM (immunoreceptor tyrosine-based inhibition motif) domains that associate with phosphatases Shp1 and Shp-2, leading to immune suppression (85). Hsp70 has been shown to bind to Siglecs after tissue damage suggesting a mechanisms for the immunosuppressive roles of the chaperone (86). A further complication to this scenario is that human cells can express a receptor pair SIGLEC-5 and SIGLEC-14 that can contain similar ligand binding domains and either ITIM or ITAM (immunoreceptor tyrosine-based activation motif) sequences and thus, dependent on context, are either immunosuppressive (SIGLEC-5) or immunostimulatory (SIGLEC-14) (87). Clearly further studies are essential to clarify the nature of the signaling complexes on mononuclear phagocytes that determine response to HSPs in terms of both endocytosis and inflammatory cell signaling.

\section{CONCLUSIONS}

(a) The scavenger receptors LOX-1 and SCARF1 mediate binding and endocytosis of HSPs such as Hsp70, Hsp90, and Hsp110. The HSPs are taken up by a clathrin-independent mechanism involving the GEEC pathway. At least in the case of SCARF1, endocytosis requires the activity of the c-Src kinase which can bind to the receptor in lipid raft microdomains.

(b) Uptake by scavenger receptors may be a component of the detoxification pathways, with the effect of removing inflammatory and immune-stimulatory HSP-peptide complexes, particularly in the context of tissue injury. This process may also be beneficial in the activities of molecular chaperone-based vaccines in which the HSPs enhance antigen uptake, integrity and cross-presentation to CD8+ T lymphocytes.

(c) The scavenger receptors localize to lipid raft microdomains on the mononuclear phagocyte cell surface after HSP binding. This process may facilitate endocytosis through the GEEC pathway by bringing the SR in close proximity to c-Src and CDC42. In addition, concentration of scavenger receptors in lipid rafts with TLR4 and other regulatory proteins may trigger inflammatory signaling and cytokine synthesis after HSP binding.

Three HSP binding receptors SCARF1/SREC-I, FEEL-1, and LOX-1 are shown as well as related proteins. Locations of atypical EGF-like domains are indicated in-CED-1, hSCARF1, hFEELI/Stabilin-1 and MEGF10. Each share EGF-like consensus repeats in the extracellular domains. Tyrosine-based sorting signals are known to interact with the phospho-tyrosine domain of clathrin adaptors (NPXY for CED-1, FXNPXY and YXXØ for hMEGF10) are shown in the figure. SCARF1 does not contain these motifs and is not internalized through clathrin-mediated endocytosis. FEEL-1 is expressed mainly in intracellular compartments. A dileucine based (DXXLL for hFEEL-1) sorting signal is present in the cytosolic tails of hFEEL-1 and can also be found in mannose 6-phosphate receptors that mediate sorting between trans-Golgi network (TGN) and endosomes. LOX-1, although sharing many properties with SCARF1, including HSP binding and internalization, does not contain EGF-like motifs in its extracellular domain extracellular domain and belongs to the C-type lectin family.

Under resting conditions, SCARF1 is shown in the bulk membrane domain containing a range of surface proteins which are either transmembrane proteins such as SCARF1, GPI-AP proteins or proteins anchored to the inside of the membrane such as c-Src. Upon Hsp90a binding, SCARF1 becomes localized into lipid raft domains and co-localized with c-Src. Within $5 \mathrm{~min}$ of ligand binding, Hsp90 $\alpha$-SCARF1 complexes enter the GEEC compartment and are internalized (36). We also show proteins that remain in the bulk membrane and are not internalized through the GEEC pathway.

We show ligand (HSP) binding by SCARF1 leading to its recruitment to lipid raft microdomains in the plasma membrane. SCARF1 then coordinates interaction of c-Src, CDC42 and TLR4 and signaling through the NF-kB and MAP kinase pathways upstream of inflammatory cytokine expression.

\section{AUTHOR CONTRIBUTIONS}

All authors listed have made a substantial, direct and intellectual contribution to the work, and approved it for publication. 


\section{FUNDING}

This work was supported by NIH grants RO1CA119045 and RO1CA047407.

\section{REFERENCES}

1. Richter K, Haslbeck M, Buchner J. The heat shock response: life on the verge of death. Mol Cell. (2010) 40:253-66. doi: 10.1016/j.molcel.2010.10.006

2. Salari S, Seibert T, Chen YX, Hu T, Shi C, Zhao X, et al. Extracellular HSP27 acts as a signaling molecule to activate NF-kappaB in macrophages. Cell Stress Chaperones. (2013) 18:53-63. doi: 10.1007/s12192-012-0356-0

3. Cohen-Sfady M, Nussbaum G, Pevsner-Fischer M, Mor F, Carmi P, ZaninZhorov A, et al. Heat shock protein 60 activates B cells via the TLR4-MyD88 pathway. J Immunol. (2005) 175:3594-602. doi: 10.4049/jimmunol.175.6.3594

4. Moran Luengo T, Mayer MP, Rudiger SG. The Hsp70-Hsp90 chaperone cascade in protein folding. Trends Cell Biol. (2019) 29:164-77. doi: 10.1016/j.tcb.2018.10.004

5. Rüdiger S, Buchberger A, Bukau B. Interaction of Hsp70 chaperones with substrates. Nat Struct Biol. (1997) 4:342-9. doi: 10.1038/nsb0597-342

6. Mambula SS, Calderwood SK. Heat induced release of Hsp70 from prostate carcinoma cells involves both active secretion and passive release from necrotic cells. Int J Hyperthermia. (2006) 22:575-85. doi: 10.1080/02656730600976042

7. Chalmin F, Ladoire S, Mignot G, Vincent J, Bruchard M, Remy-Martin JP, et al. Membrane-associated Hsp72 from tumor-derived exosomes mediates STAT3-dependent immunosuppressive function of mouse and human myeloid-derived suppressor cells. J Clin Invest. (2010) 120:457-71. doi: 10.1172/JCI40483

8. Gong J, Zhang Y, Durfee J, Weng D, Liu C, Koido S, et al. A heat shock protein 70-based vaccine with enhanced immunogenicity for clinical use. J Immunol. (2010) 184:488-96. doi: 10.4049/jimmunol.0902255

9. Guo C, Subjeck JR, Wang XY. Creation of recombinant chaperone vaccine using large heat shock protein for antigen-targeted cancer immunotherapy. Methods Mol Biol. (2018) 1709:345-57. doi: 10.1007/978-1-4939-7477-1 25

10. Murshid A, Theriault J, Gong J, Calderwood SK. Investigating receptors for extracellular heat shock proteins. Methods Mol Biol. (2011) 787:289-302. doi: 10.1007/978-1-61779-295-3_22

11. Delneste Y, Magistrelli G, Gauchat J, Haeuw J, Aubry J, Nakamura K, et al. Involvement of LOX-1 in dendritic cell-mediated antigen cross-presentation. Immunity. (2002) 17:353-62. doi: 10.1016/S1074-7613(02)00388-6

12. Facciponte JG, MacDonald IJ, Wang XY, Kim H, Manjili MH, Subjeck JR. Heat shock proteins and scavenger receptors: role in adaptive immune responses. Immunol Invest. (2005) 34:325-42. doi: 10.1081/IMM-200064505

13. Murshid A, Gong J, Calderwood SK. The role of heat shock proteins in antigen cross presentation. Front Immunol. (2012) 3:63. doi: 10.3389/fimmu.2012.00063

14. Murshid A, Gong J, Calderwood SK. Hsp90-peptide complexes stimulate antigen presentation through the class II pathway after binding scavenger receptor SREC-Immunobiology I. (2014) 219:924-31. doi: 10.1016/j.imbio.2014.08.001

15. Murshid A, Borges TJ, Lang BJ, Calderwood SK. The scavenger receptor SREC-I cooperates with toll-like receptors to trigger inflammatory innate immune responses. Front Immunol. (2016) 7:226. doi: 10.3389/fimmu.2016.00226

16. Gao P, Sun X, Chen X, Wang Y, Foster BA, Subjeck J, et al. Secretable chaperone Grp170 enhances therapeutic activity of a novel tumor suppressor, mda-7/IL-24. Cancer Res. (2008) 68:3890-8. doi: 10.1158/0008-5472.CAN-08-0156

17. Manjili MH, Wang XY, Chen X, Martin T, Repasky EA, Henderson R, et al. HSP110-HER2/neu chaperone complex vaccine induces protective immunity against spontaneous mammary tumors in HER-2/neu transgenic mice. $J$ Immunol. (2003) 171:4054-61. doi: 10.4049/jimmunol.171.8.4054

18. Ellis RJ. Protein misassembly: macromolecular crowding and molecular chaperones. Adv Exp Med Biol. (2007) 594:1-13. doi: 10.1007/978-0-387-39975-1_1

\section{ACKNOWLEDGMENTS}

We thank the Department of Radiation Oncology, Beth Israel Deaconess Medical Center for the encouragement and support.

19. Lindquist S, Craig EA. The heat-shock proteins. Annu Rev Genet. (1988) 22:631-77. doi: 10.1146/annurev.ge.22.120188.003215

20. Mambula SS, Stevenson MA, Ogawa K, Calderwood SK. Mechanisms for Hsp70 secretion: crossing membranes without a leader. Methods. (2007) 43:168-75. doi: 10.1016/j.ymeth.2007.06.009

21. Mambula SS, Calderwood SK. Heat shock protein 70 is secreted from tumor cells by a nonclassical pathway involving lysosomal endosomes. J Immunol. (2006) 177:7849-57. doi: 10.4049/jimmunol.177.11.7849

22. Lancaster GI, Febbraio MA. Exosome-dependent trafficking of HSP70: a novel secretory pathway for cellular stress proteins. J Biol Chem. (2005) 280:23349-55. doi: 10.1074/jbc.M502017200

23. Eguchi T, Sogawa C, Okusha Y, Uchibe K, Iinuma R, Ono K, et al. Organoids with cancer stem cell-like properties secrete exosomes and HSP90 in a 3D nanoenvironment. PLoS ONE. (2018) 13:e0191109. doi: 10.1371/journal.pone.0191109

24. Asea A, Kraeft SK, Kurt-Jones EA, Stevenson MA, Chen LB, Finberg RW, et al. HSP70 stimulates cytokine production through a CD14-dependant pathway, demonstrating its dual role as a chaperone and cytokine. Nat Med. (2000) 6:435-42. doi: 10.1038/74697

25. Li W, Li Y, Guan S, Fan J, Cheng CF, Bright AM, et al. Extracellular heat shock protein-90alpha: linking hypoxia to skin cell motility and wound healing. EMBO J. (2007) 26:1221-33. doi: 10.1038/sj.emboj. 7601579

26. Tsen F, Bhatia A, O'Brien K, Cheng CF, Chen M, Hay N, et al. Extracellular heat shock protein 90 signals through subdomain II and the NPVY motif of LRP-1 receptor to Akt1 and Akt2: a circuit essential for promoting skin cell migration in vitro and wound healing in vivo. Mol Cell Biol. (2013) 33:4947-59. doi: 10.1128/MCB.00559-13

27. Weng D, Calderwood SK, Gong J. Preparation of a heat-shock protein 70based vaccine from DC-tumor fusion cells. Methods Mol Biol. (2011) 787:25565. doi: 10.1007/978-1-61779-295-3_19

28. Gong J, Zhu B, Murshid A, Adachi H, Song B, Lee A, et al. T cell activation by heat shock protein 70 vaccine requires TLR signaling and scavenger receptor expressed by endothelial cells-1. J Immunol. (2009) 183:3092-8. doi: 10.4049/jimmunol.0901235

29. Enomoto Y, Bharti A, Khaleque AA, Song B, Liu C, Apostolopoulos V, et al. Enhanced immunogenicity of heat shock protein 70 peptide complexes from dendritic cell-tumor fusion cells. J Immunol. (2006) 177:5946-55. doi: 10.4049/jimmunol.177.9.5946

30. Thériault JR, Adachi H, Calderwood SK. Role of scavenger receptors in the binding and internalization of heat shock protein 70. J Immunol. (2006) 177:8604-11. doi: 10.4049/jimmunol.177.12.8604

31. Basu S, Binder RJ, Ramalingam T, Srivastava PK. CD91 is a common receptor for heat shock proteins gp96, hsp90, hsp70, and calreticulin. Immunity. (2001) 14:303-13. doi: 10.1016/S1074-7613(01)00111-X

32. Cheng CF, Fan J, Fedesco M, Guan S, Li Y, Bandyopadhyay B, et al. Transforming growth factor alpha (TGFalpha)-stimulated secretion of HSP90alpha: using the receptor LRP-1/CD91 to promote human skin cell migration against a TGFbeta-rich environment during wound healing. $\mathrm{Mol}$ Cell Biol. (2008) 28:3344-58. doi: 10.1128/MCB.01287-07

33. Zani IA, Stephen SL, Mughal NA, Russell D, Homer-Vanniasinkam $S$, Wheatcroft SB, et al. Scavenger receptor structure and function in health and disease. Cells. (2015) 4:178-201. doi: 10.3390/cells40 20178

34. Chen M, Masaki T, Sawamura T. LOX-1, the receptor for oxidized low-density lipoprotein identified from endothelial cells: implications in endothelial dysfunction and atherosclerosis. Pharmacol Ther. (2002) 95:89100. doi: 10.1016/S0163-7258(02)00236-X

35. Adachi $\mathrm{H}$, Tsujimoto $\mathrm{M}$. Structure and function of a novel scavenger receptor expressed in human endothelial cells. Tanpakushitsu Kakusan Koso. (1999) 44(8 Suppl):1282-6. 
36. Murshid A, Gong J, Calderwood SK. Heat shock protein 90 mediates efficient antigen cross presentation through the scavenger receptor expressed by endothelial cells-I. J Immunol. (2010) 185:2903-17. doi: 10.4049/jimmunol.0903635

37. Cloutier P, Coulombe B. Regulation of molecular chaperones through posttranslational modifications: decrypting the chaperone code. Biochim Biophys Acta. (2013) 1829:443-54. doi: 10.1016/j.bbagrm.2013.02.010

38. Nitika, Truman AW. Cracking the chaperone code: cellular roles for Hsp70 phosphorylation. Trends Biochem Sci. (2017) 42:932-5. doi: $10.1016 /$ j.tibs.2017.10.002

39. Ohki I, Ishigaki T, Oyama T, Matsunaga S, Xie Q, Ohnishi-Kameyama M, et al. Crystal structure of human lectin-like, oxidized low-density lipoprotein receptor 1 ligand binding domain and its ligand recognition mode to OxLD. Structure. (2005) 13:905-17. doi: 10.1016/j.str.2005.03.016

40. Ishigaki T, Ohki I, Oyama T, Machida S, Morikawa K, Tate S. Purification, crystallization and preliminary X-ray analysis of the ligand-binding domain of human lectin-like oxidized low-density lipoprotein receptor 1 (LOX-1). Acta Crystallogr Sect F Struct Biol Cryst Commun. (2005) 61(Pt 5):524-7. doi: $10.1107 /$ S1744309105012042

41. Thakkar S, Wang X, Khaidakov M, Dai Y, Gokulan K, Mehta JL, et al. Structure-based design targeted at LOX-1, a receptor for oxidized low-density lipoprotein. Sci Rep. (2015) 5:16740. doi: 10.1038/srep16740

42. Francone $\mathrm{OL}, \mathrm{Tu} \mathrm{M}$, Royer $\mathrm{LJ}$, Zhu J, Stevens $\mathrm{K}$, Oleynek JJ, et al. The hydrophobic tunnel present in LOX-1 is essential for oxidized LDL recognition and binding. J Lipid Res. (2009) 50:546-55. doi: 10.1194/jlr.M800474-JLR200

43. Kottke T, Pulido J, Thompson J, Sanchez-Perez L, Chong H, Calderwood SK, et al. Antitumor immunity can be uncoupled from autoimmunity following heat shock protein 70 -mediated inflammatory killing of normal pancreas. Cancer Res. (2009) 69:7767-74. doi: 10.1158/0008-5472.CAN-09-1597

44. Kottke T, Sanchez-Perez L, Diaz RM, Thompson J, Chong H, Harrington K, et al. Induction of hsp70-mediated Th17 autoimmunity can be exploited as immunotherapy for metastatic prostate cancer. Cancer Res. (2007) 67:119709. doi: 10.1158/0008-5472.CAN-07-2259

45. Oka K, Sawamura T, Kikuta K, Itokawa S, Kume N, Kita T, et al. Lectinlike oxidized low-density lipoprotein receptor 1 mediates phagocytosis of aged/apoptotic cells in endothelial cells. Proc Natl Acad Sci USA. (1998) 95:9535-40. doi: 10.1073/pnas.95.16.9535

46. Ramirez-Ortiz ZG, Pendergraft WF, Prasad A, Byrne MH, Iram T, Blanchette CJ, et al. The scavenger receptor SCARF1 mediates the clearance of apoptotic cells and prevents autoimmunity. Nat Immunol. (2013) 14:917-26. doi: $10.1038 /$ ni.2670

47. Zhou Z, Hartwieg E, Horvitz HR. CED-1 is a transmembrane receptor that mediates cell corpse engulfment in C. elegans. Cell. (2001) 104:43-56. doi: 10.1016/S0092-8674(01)00190-8

48. Suzuki E, Nakayama M. MEGF10 is a mammalian ortholog of CED-1 that interacts with clathrin assembly protein complex 2 medium chain and induces large vacuole formation. Exp Cell Res. (2007) 313:3729-42. doi: 10.1016/j.yexcr.2007.06.015

49. Suzuki E, Nakayama M. The mammalian Ced-1 ortholog MEGF10/KIAA1780 displays a novel adhesion pattern. Exp Cell Res. (2007) 313:2451-64. doi: 10.1016/j.yexcr.2007.03.041

50. McPhee CK, Baehrecke EH. The engulfment receptor Draper is required for autophagy during cell death. Autophagy. (2010) 6:1192-3. doi: 10.4161 /auto.6.8.13474

51. Wu HH, Bellmunt E, Scheib JL, Venegas V, Burkert C, Reichardt LF, et al. Glial precursors clear sensory neuron corpses during development via Jedi-1, an engulfment receptor. Nat Neurosci. (2009) 12:1534-41. doi: 10.1038/nn.2446

52. Murshid A, Theriault J, Gong J, Calderwood SK. Molecular chaperone receptors. Methods Mol Biol. (2018) 1709:331-44. doi: 10.1007/978-1-4939-7477-1_24

53. Kaksonen M, Roux A. Mechanisms of clathrin-mediated endocytosis. Nat Rev Mol Cell Biol. (2018) 19:313-26. doi: 10.1038/nrm.2017.132

54. Williams TM, Lisanti MP. The Caveolin genes: from cell biology to medicine. Ann Med. (2004) 36:584-95. doi: 10.1080/07853890410018899

55. Twigg MW, Freestone K, Homer-Vanniasinkam S, Ponnambalam S. The LOX-1 scavenger receptor and its implications in the treatment of vascular disease. Cardiol Res Pract. (2012) 2012: 632408. doi: 10.1155/2012/632408
56. Saha S, Anilkumar AA, Mayor S. GPI-anchored protein organization and dynamics at the cell surface. J Lipid Res. (2016) 57:159-75. doi: 10.1194/jlr.R062885

57. Mayor S, Riezman H. Sorting GPI-anchored proteins. Nat Rev Mol Cell Biol. (2004) 5:110-20. doi: 10.1038/nrm1309

58. Kalia M, Kumari S, Chadda R, Hill MM, Parton RG, Mayor S. Arf6independent GPI-anchored protein-enriched early endosomal compartments fuse with sorting endosomes via a Rab5/phosphatidylinositol-3'kinase-dependent machinery. Mol Biol Cell. (2006) 17:3689-704. doi: 10.1091/mbc.e05-10-0980

59. Sabharanjak S, Sharma P, Parton RG, Mayor S. GPI-anchored proteins are delivered to recycling endosomes via a distinct cdc42-regulated, clathrin-independent pinocytic pathway. Dev Cell. (2002) 2:411-23. doi: 10.1016/S1534-5807(02)00145-4

60. Chadda R, Howes MT, Plowman SJ, Hancock JF, Parton RG, Mayor S. Cholesterol-sensitive $\mathrm{Cdc} 42$ activation regulates actin polymerization for endocytosis via the GEEC pathway. Traffic. (2007) 8:702-17. doi: 10.1111/j.1600-0854.2007.00565.x

61. Saha S, Lee IH, Polley A, Groves JT, Rao M, Mayor S. Diffusion of GPIanchored proteins is influenced by the activity of dynamic cortical actin. Mol Biol Cell. (2015) 26:4033-45. doi: 10.1091/mbc.E15-06-0397

62. Sezgin E, Levental I, Grzybek M, Schwarzmann G, Mueller V, Honigmann A, et al. Partitioning, diffusion, and ligand binding of raft lipid analogs in model and cellular plasma membranes. Biochim Biophys Acta. (2012) 1818:1777-84. doi: 10.1016/j.bbamem.2012.03.007

63. Simons K, Ehehalt R. Cholesterol, lipid rafts, and disease. J Clin Invest. (2002) 110:597-603. doi: 10.1172/JCI16390

64. Pang T, Wang J, Benicky J, Saavedra JM. Minocycline ameliorates LPS-induced inflammation in human monocytes by novel mechanisms including LOX1, Nur77 and LITAF inhibition. Biochim Biophys Acta. (2012) 1820:503-10. doi: 10.1016/j.bbagen.2012.01.011

65. Neefjes JJ, Momburg F, Hämmerling GJ. Selective and ATP-dependent translocation of peptides by the MHC-encoded transporter. Science. (1993) 261:769-71. doi: 10.1126/science.8342042

66. Bonifaz L, Bonnyay D, Mahnke K, Rivera M, Nussenzweig MC, Steinman RM. Efficient targeting of protein antigen to the dendritic cell receptor DEC-205 in the steady state leads to antigen presentation on major histocompatibility complex class I products and peripheral CD8+ T cell tolerance. J Exp Med. (2002) 196:1627-38. doi: 10.1084/jem.20021598

67. Burgdorf S, Kurts C. Endocytosis mechanisms and the cell biology of antigen presentation. Curr Opin Immunol. (2008) 20:89-95. doi: $10.1016 /$ j.coi.2007.12.002

68. Burgdorf S, Lukacs-Kornek V, Kurts C. The mannose receptor mediates uptake of soluble but not of cell-associated antigen for cross-presentation. $J$ Immunol. (2006) 176:6770-6. doi: 10.4049/jimmunol.176.11.6770

69. Idoyaga J, Lubkin A, Fiorese C, Lahoud MH, Caminschi I, Huang Y, et al. Comparable T helper 1 (Th1) and CD8 T-cell immunity by targeting HIV gag p24 to CD8 dendritic cells within antibodies to Langerin, DEC205, and Clec9A. Proc Natl Acad Sci USA. (2011) 108:2384-9. doi: $10.1073 /$ pnas. 1019547108

70. Tacken PJ, Ginter W, Berod L, Cruz LJ, Joosten B, Sparwasser T, et al. Targeting DC-SIGN via its neck region leads to prolonged antigen residence in early endosomes, delayed lysosomal degradation, and cross-presentation. Blood. (2011) 118:4111-9. doi: 10.1182/blood-2011-04-346957

71. Oura J, Tamura Y, Kamiguchi K, Kutomi G, Sahara H, Torigoe T, et al. Extracellular heat shock protein 90 plays a role in translocating chaperoned antigen from endosome to proteasome for generating antigenic peptide to be cross-presented by dendritic cells. Int Immunol. (2011) 23:223-37. doi: 10.1093/intimm/dxq475

72. Poole K, Meder D, Simons K, Müller D. The effect of raft lipid depletion on microvilli formation in MDCK cells, visualized by atomic force microscopy. FEBS Lett. (2004) 565:53-8. doi: 10.1016/j.febslet.2004.03.095

73. Murshid A, Gong J, Prince T, Borges TJ, Calderwood SK. Scavenger receptor SREC-I mediated entry of TLR4 into lipid microdomains and triggered inflammatory cytokine release in RAW 264.7 cells upon LPS activation. PLoS ONE. (2015) 10:e0122529. doi: 10.1371/journal.pone.0122529

74. Jeannin P, Bottazzi B, Sironi M, Doni A, Rusnati M, Presta M, et al. Complexity and complementarity of outer membrane protein A recognition 
by cellular and humoral innate immunity receptors. Immunity. (2005) 22:55160. doi: 10.1016/j.immuni.2005.03.008

75. Beauvillain C, Meloni F, Sirard JC, Blanchard S, Jarry U, Scotet M, et al. The scavenger receptors SRA-1 and SREC-I cooperate with TLR2 in the recognition of the hepatitis $\mathrm{C}$ virus non-structural protein 3 by dendritic cells. J Hepatol. (2010) 52:644-51. doi: 10.1016/j.jhep.2009.11.031

76. Murshid A, Gong J, Ahmad R, Borges TJ, Calderwood SK. Scavenger receptor SREC-I promotes double stranded RNA-mediated TLR3 activation in human monocytes. Immunobiology. (2015) 220:823-32. doi: 10.1016/j.imbio.2014.12.011

77. Means TK. Fungal pathogen recognition by scavenger receptors in nematodes and mammals. Virulence. (2010) 1:37-41. doi: 10.4161/viru.1.1.10228

78. Means TK, Mylonakis E, Tampakakis E, Colvin RA, Seung E, Puckett L, et al. Evolutionarily conserved recognition and innate immunity to fungal pathogens by the scavenger receptors SCARF1 and CD36. J Exp Med. (2009) 206:637-53. doi: 10.1084/jem.20082109

79. Calderwood SK, Gong J, Murshid A. Extracellular HSPs: the complicated roles of extracellular HSPs in immunity. Front Immunol. (2016) 7:159. doi: 10.3389/fimmu.2016.00159

80. Rozhkova E, Yurinskaya M, Zatsepina O, Garbuz D, Karpov V, Surkov $S$, et al. Exogenous mammalian extracellular HSP70 reduces endotoxin manifestations at the cellular and organism levels. Ann N Y Acad Sci. (2010) 1197:94-107. doi: 10.1111/j.1749-6632.2009.05375.x

81. Calderwood SK, Murshid A, Gong J. Heat shock proteins: conditional mediators of inflammation in tumor immunity. Front Immunol. (2012) 3:75. doi: 10.3389/fimmu.2012.00075

82. Borges TJ, Murakami N, Machado FD, Murshid A, Lang BJ, Lopes RL, et al. March1-dependent modulation of donor MHC II on CD103(+) dendritic cells mitigates alloimmunity. Nat Commun. (2018) 9:3482. doi: $10.1038 / s 41467-018-05572-z$
83. Macauley MS, Crocker PR, Paulson JC. Siglec-mediated regulation of immune cell function in disease. Nat Rev Immunol. (2014) 14:653-66. doi: $10.1038 /$ nri3737

84. Calderwood SK, Murshid A. Siglecs take a TOLL on inflammation: deciphering the Hsp70 riddle. EMBO J. (2015) 34:2733-4. doi: $10.15252 / \mathrm{embj} .201593172$

85. Whitney G, Wang $\mathrm{S}$, Chang $\mathrm{H}$, Cheng $\mathrm{KY}, \mathrm{Lu} \mathrm{P}$, Zhou XD, et al. A new siglec family member, siglec-10, is expressed in cells of the immune system and has signaling properties similar to CD33. Eur J Biochem. (2001) 268:6083-96. doi: 10.1046/j.0014-2956.2001.0 2543.x

86. Chen GY, Tang J, Zheng P, Liu Y. CD24 and Siglec-10 selectively repress tissue damage-induced immune responses. Science. (2009) 323:1722-5. doi: $10.1126 /$ science. 1168988

87. Fong JJ, Sreedhara K, Deng L, Varki NM, Angata T, Liu Q, et al Immunomodulatory activity of extracellular $\mathrm{Hsp} 70$ mediated via paired receptors Siglec-5 and Siglec-14. EMBO J. (2015) 34:2775-88. doi: 10.15252/embj.201591407

Conflict of Interest: The authors declare that the research was conducted in the absence of any commercial or financial relationships that could be construed as a potential conflict of interest.

Copyright $\odot 2020$ Murshid, Borges, Bonorino, Lang and Calderwood. This is an open-access article distributed under the terms of the Creative Commons Attribution License (CC BY). The use, distribution or reproduction in other forums is permitted, provided the original author(s) and the copyright owner(s) are credited and that the original publication in this journal is cited, in accordance with accepted academic practice. No use, distribution or reproduction is permitted which does not comply with these terms. 